\title{
Current in vitro assay to determine bacterial biofilm formation of clinical isolates
}

\author{
Titik Nuryastuti* \\ Microbiology Department, Faculty of Medicine, Universitas Gadjah Mada, Yogyakarta, \\ Indonesia
}

\begin{abstract}
Biofilm mode of growth is bacterial lifestyle widespread in microbial world and represents a concern in health care. Recently, serious problem concerning biofilm-related infection is increasing significantly. However complexity of biofilm makes it difficult to conduct proper analysis. Although biofilm represents a major challenge for microbiologist, methods aimed to determine biofilm formation and development are not standardized yet. The aim of the present review was to provide an overview of the advantages and disadvantages of the difference in vitro methods for determining biofilm forming ability of clinical isolates.
\end{abstract}

\section{ABSTRAK}

Pertumbuhan bakteri dalam kondisi biofilm merupakan salah satu strategi pertahanan yang dilakukan oleh berbagai spesies mikroorganisme. Akhir-akhir ini dijumpai masalah serius sehubungan dengan meningkatnya kasus infeksi terkait biofilm secara signifikan. Namun kompleksitas struktur biofilm, menyebabkan analisa dan deteksi pembentukan biofilm pada bakteri sulit dilakukan. Meskipun biofilm dianggap sebagai tantangan utama bagi ahli mikrobiologi, metode-metode yang selama ini dikerjakan belum terstandarisasi dengan baik. Tujuan dari review ini adalah untuk memberikan gambaran tentang manfaat dan kerugian dari berbagai uji in vitro untuk penentuan kemampuan pembentukan biofilm pada isolat klinis.

Keywords: biofilm formation - in vitro assay - clinical isolates

\section{INTRODUCTION}

Bacterial biofilms are complex, mono- or poly-microbial communities adhering to biotic or abiotic surfaces. This adaptation has been implicated as a survival strategy. The formation of biofilms is mediated by mechanical, biochemical and genetical factors. The biofilms enhance the virulence of the pathogen and have their potential role in various infections. This miniature ecosystem provides a safe home for the members of the community, where they are untouched by the counter-defense mechanisms of host immune responses, phagocytosis and antibiotic treatment. ${ }^{1}$ Biofilm formation has been observed by most of the bacteria found in natural, clinical and industrial setup. A biofilm or slime, is regarded as microbial derived sessile communities characterized by the cells that are irreversibly attached to a substratum or to each other. ${ }^{2}$ They are embedded in a matrix of extracellular polymeric substances (EPS) they have produced, and exhibit an altered phenotype with respect to growth rate and gene transcription.

\footnotetext{
* corresponding author: t.nuryastuti@ugm.ac.id
} 
Biofilms are notoriously difficult to eradicate and are a source of many recalcitrant infections. Microorganisms growing in a biofilm are more resistant to antimicrobial agents than planktonic cells. High antimicrobial concentrations are required to inactivate organisms growing in a biofilm, as antibiotic resistance can increase 1,000 fold. It has been well documented that biofilms add to the virulence of the pathogen. It has been estimated that the frequency of infections caused by biofilms, especially in the developed world, lies between $65 \%$ and $80 \%$ as per reports from Centres for Disease Control and Prevention (CDC) and National Institutes of Health (NIH), respectively. ${ }^{3}$ Biofilm-related infection oftenly resulted in chronic and persisten infection. It associated with many medical conditions including indwelling medical devices-related infection, dental plaque, upper respiratory tract infections, lung infection, otitis media, peritonitis, otitis media and urogenital infections. Both Gram-positive and Gramnegative bacteria have the capability to form biofilms. Bacteria commonly involved include Enterococcus faecalis, Staphylococcus aureus,
Staphylococcus epidermidis, Streptococcus viridans, Escherichia coli, Klebsiella pneumoniae, Salmonella spp, Proteus mirabilis, Pseudomonas aeruginosa, and Acinetobacter spp. ${ }^{4,5}$

The interior of the bacterial biofilms presents greater resistance to the opsonization by antibodies and to phagocytosis, which explains the chronic character of these infections. Under certain circumstances such as deprivation of nutrition or a heavy shearing forces, detachment and dissemination of biofilm cells occurs resulted in the release and dispersal of bacterial cell from biofilm colonization. Therefore, biofilm formation of microorganism arises a great significance impact in many areas such as the emergence of antimicrobial resistance, persistent and recurrent infections, medical device-related infections. Many researchers reported that indwelling medical devices associated with biofilm-related infection (TABLE 1). Moreover, the bacterial biofilm phenotype is a potential virulence factor which may contribute to the clinical relapse of infections. ${ }^{6}$

TABLE 1. Indwelling medical devices associated with biofilm-related infection ${ }^{6}$

\begin{tabular}{clrl}
\hline No, & Medical devices & No, & Medical devices \\
\hline 1. & Intravenous catheter & 9. & Contact lenses \\
2. & Endotracheal tube & 10, & Intrauterine device \\
3. Mechanical heart valves & 11. & Pacemaker \\
4. & Peritoneal dyalisis hemodialisa & 12. & Prosthetic joint \\
5. Urinary catheter & 13, & Tympanostomi tubes \\
6. & Voice prostheses & 14. & Berast implant \\
7. Penile implant & 15, & Vascular graft \\
8. & Biliary stents & 16. & Orthopedic devices \\
& & & (fixators, nails, screw) \\
\hline
\end{tabular}

Biofilm-related infection represents a major challenge in both microbiological and hygiene areas, the enumeration of the actual number of bacteria in biofilm, including approriate method for biofilm forming determination is still a great challenge for microbiologists. Considering the complexity and heterogeneity of biofilm structure, the exact objective of investigation 
must be taken into account. The capability of isolates to form a biofilm, amount of EPS, the total number of bacterial cells embedded in biofilm, the effective number of living bacteria in biofilm, or the antibiotic sensitivity pattern of biofilm cells compared than planktonic mode of growth, must be considered as different objective requiring different experimental approaches. Taking into account these considerations, in this paper, the simple assay as well as some sophisticated methods to determine bacterial biofilm forming ability are reviewed.

\section{Detection Methods of Biofilm Forming Abilities}

Accurate diagnosis is the key to better understanding the biofilm. The identification of biofilms in persistent infections may assist in deciding suitable therapies. A number of test are avalaible to detect biofilm production of microorganism, but they aren't wellstandardized yet. Basically, it can be distinguished into phenotypic and genotypic assay, or based on cell number quantification, it is divided into qualitative and quantitative methods.

\section{Tube method (TM)}

A qualitative assessment of biofilm formation was determined as previously described by Christensen et al. ${ }^{7}$ It was a conventional assay using Trypton Soya Broth (TSB) inoculated with a loopful of microorganism from overnight culture plates and incubated for 24 hours at $37^{\circ} \mathrm{C}$. The tubes were decanted and washed with Phosphat Buffer Saline (PBS) (pH 7.3) and dried. Furthermore the dried tubes were stained with crystal violet $(0.1 \%)$. Excess stain was removed and tubes were washed off with deionized water. Tubes were than dried in inverted position and observed for biofilm formation. It was considered positive when a visible film lined the wall and bottom of the tube. It was found that some staphylococci formed a bacterial or slime layer on the walls of a culture tube, ${ }^{7}$ but the assessment of the ability of the strains to form biofilm was observer dependent and highly qualitative. $^{8}$

\section{Congo Red Agar (CRA)}

Tube method was not always successful for detecting weak slime production and variations in media may affect the result. ${ }^{7}$ Congo Red Agar was used as new alternative method for detecting slime production by coagulase negative staphylococci and more reliable than Christensen method. ${ }^{9}$ Freeman et al. ${ }^{9}$ had described an alternative method of screening biofilm formation by Staphylococcus isolates; which requires the use of a specially prepared solid medium i.e. Brain Heart Infusion Broth (BHI) supplemented with 5\% sucrose and Congo red. The medium was composed of BHI (37 gr/ $\mathrm{L})$, sucrose (50 gr/L), Bacto agar (10 g2/L) and Congo red stain $(0.8 \mathrm{gr} / \mathrm{L})$. Congo red was prepared as concentrated aqueous solution and autoclaved at $121^{\circ} \mathrm{C}$ for 15 minutes, separately from other medium constituents and was then added when the agar had cooled to $55^{\circ} \mathrm{C}$. Plates were inoculated and incubated aerobically for 24 to 48 at $37^{\circ} \mathrm{C}$. Positive result was indicated by black colonies with a dry crystalline consistency. Weak slime producers usually remained pink, though occasional darkening at the centers of colonies was observed. A darkening of the colonies with the absence of a dry crystalline colonial morphology indicated an indeterminate result.

Determination of biofilm forming using this media has also been shortcoming in variations in black pigment formation. However, modification on the agar constituent is 
hypothesized to improve the outcome on biofilm identity determination. Based on Mariana et al. ${ }^{10}$ studying 100 isolates of MRSA, the phenotypic coloration on agar improved upon modification of agar ingredients, which is proposed by changing the concentration of Congo red dye and saccharose, omission of glucose. The reduction in the concentration of agar constituents resulted in permanent formation of intense black pigment in isolates with ica $A$ and $D$ genes, without any decreased in pigmentation over time. The agar constituent modification allowed stability of black pigment formation and also reduced agar preparation cost. Stable black pigment is an added value to the identification accuracy of biofilm-forming determination. ${ }^{10}$ However, it was reported that CRA method showed very little correlation with either of tube or tissue culture plate method and the parameters of sensitivity (7.6 \%), specificity (97.2\%) and accuracy (51.3\%) were very low. Screening on CRA does not correlate well with corresponding methods for detecting biofilm formation in staphylococci. ${ }^{11}$

\section{Tissue Culture Plate method (TCP) and Crystal Violet (CV) staining}

Tissue culture plate method is most widely used and was considered as standard test for detection of biofilm formation. It was aimed to quantify the biofilm more objectively. In this assay, microorganisms were grown in the wells of microtiter plates and may or may not form a biofilm on the bottom and the walls of the wells. Mostly, no defined adhesion step is used prior biofilm formation, since in most assays the microorganisms are directly suspended in growth medium. After removal of the planktonic cells and staining of the surface-attached cells with, for example, crystal violet, the amount of biofilm in each well is quantified by determining the absorbance of the stained biofilm. The absorbance of the stained biofilm can be determined directly or after solubilization of the retained stain and is used to classify ability of the strains tested to form biofilm. Optical density (OD) of stained adherent bacteria were determined with a micro ELISA reader at wavelength of $570 \mathrm{~nm}$ (OD570 nm). These OD values were considered as an index of bacteria adhering to surface and forming biofilms. Determination of biofilm formation to polystyrene petri dishes using crystal violet staining followed by spectrophotometric absorbance measurements was first performed by Fletcher et al. ${ }^{12}$

Crytal violet staining is also one of the first methods adopted for biofilm biomass quantification. ${ }^{13,14}$ Basically, this method consists in staining negatively charged molecules by the basic dye crystal violet. Crystal violet binds indifferently to negatively charged bacteria and polysaccharides of the EPS. ${ }^{15}$ After staining, the adsorbed $\mathrm{CV}$ is eluted using a solvent (e.g. ethanol or acetic acid). The amount of dye solubilised by the solvent is directly proportional to biofilm size. Crystal violet can be replaced by a more appropriate dye e.g. safranin or methylen blue. ${ }^{15,16}$ The limitations of this method are related to the low reproducibility of the method, i.e.: the experimental condition of biofilm growth, the specific nature and concentration of the solvent and the elution time, which very are crucial steps. Moreover, because both living and dead cells as well as biofilm matrix are stained by $\mathrm{CV}$, this method provides no information on the actual number of living bacteria and therefore it is poorly suitable to evaluate the anti-biofilm efficacy of antimicrobial substances.

Crystal violet is most widely used for the staining of biofilm cells and its different concentrations were used by various workers. Two different concentrations of crystal violet stain $(0.1 \%$ and $0.5 \%)$ were compared for staining of adhered fixed cells. Staining with 
$0.5 \%$ revealed better results in comparison to staining with $0.1 \%$ crystal violet for $1 \mathrm{~min}$. The results are corroborative to the finding of Stepanovic et al ${ }^{13,17}$ As listed in TABLE 2 and 3 , the interpretation of biofilm production for staphylococci has been well-reported, whereas in general some researchers also showed the cut off value for other microorganism to determine the biofilm formation result.

TABLE 2. Classification of bacterial adherence by TCP method for staphylococci ${ }^{11}$

\begin{tabular}{lll}
\hline Mcan OD values & Adherence & Biofilm formation \\
\hline 0.120 & Non & Non/weak \\
$0.120-0.240$ & Moderately & Moderate \\
$>0.240$ & Strong & High \\
\hline
\end{tabular}

TABLE 3. Interpretation of biofilm production for others bacteriae ${ }^{18}$.

\begin{tabular}{lc}
\hline OD values & Biofilm formation \\
\hline$<\mathrm{ODc} / \mathrm{ODc}<\sim<2 \mathrm{x}$ ODc* & Non/weak \\
$2 \mathrm{x}$ ODc $<\sim<4 \mathrm{x}$ ODc & Moderate \\
$>4 \mathrm{x}$ ODc & Strong \\
\hline
\end{tabular}

*ODc (optical density cut-off value) $=$ average OD of negative control $+3 x$ standard deviation (SD) of negative control.

A microtiter plate biofilm assay is often used to examine the ability of microorganisms to form biofilms, because of its simplicity and efficiency. However, different laboratories apply the assay in slightly different ways, which are unfortunately crucial to the results and conclusions drawn. Annet et al. ${ }^{8}$ has recommended the solubilization of the retained stain by the biofilms using ethanol before measuring the absorbance since it has many advantage in better determination of biofilmforming strain, which is in line the report from Stepanovic, et al. ${ }^{13}$ It is also demonstrated that the explicit inclusion of initial adhesion in the assay, as the first step in biofilm formation, yields more extensive biofilms than when biofilms were grown directly from a suspension in growth medium. When compared to TM and CRA methods, TCP can be recommended as a general screening method for detection of biofilm producing bacteria in laboratories. ${ }^{18} \mathrm{It}$ was found to be most sensitive, accurate and reproducible screening method for detection of biofilm formation and has the advantage of being a quantitative model to study the adherence of microorganism on biomedical devices. ${ }^{11}$ In addition, electron micrograph images correlate well with the biofilm production as observed by TM while CRA is not recommended for investigation of biofilm formation in Staphylococcus aureus. ${ }^{19}$

Dynamic conditions should be included as one of the key parameters in the study of in vitro biofilm formation in microtiter plates. ${ }^{20}$ Ceri et $a l .^{21}$ developed a variation of the traditional TCP model system to mimic real conditions in vivo biofilms. The Calgary Biofilm Device consists of a polystyrene lid with 96 pegs that can be fit into a standard 96-well microtiter plate, introducing an extra surface in the wells where the biofilm is to be formed and analyzed. This device is not prone to contamination and leakage, and it is more amenable to microscopic observation and control measurements. ${ }^{22}$ Recently, a "well plate microfluidic" device that allows high-throughput screening of continuous flow biofilms was described ${ }^{23}$. This dynamic system consists of microchannels integrated into a microplate, where a pneumatic pump pushes fresh medium through the microchannel (containing the biofilm) from an inlet well to an outlet well (containing spent medium). In order to simulate biofilm formation on a specific surface, several materials like glass, silicone rubber, PVC and stainless steel can be used. ${ }^{24}$ The flow cells that are most suitable to the simulation of industrial 
biofilms often have two very important features: (1) use of a large number of coupons or adhesion surfaces for biofilm formation and (2) possibility of operation at high flow rates in regimes of high turbulence and shear stress. To perform an assay using this flow cells needs a skill-trained technician and this devices usually only availabel in certain biomedical engineering laboratory.

\section{Confocal Laser Scanning Microscopy (CLSM)}

Confocal laser scanning microscopy is an optical microscope equipped with a laser beam, particularly useful in biology and life sciences to study thick samples. ${ }^{25}$ Confocal laser sanning microscopy technology make it possible to scan a thick biological sample, e.g. a microbial biofilm, by processing images, line by line, in $\mathrm{X}, \mathrm{Y}$ and $\mathrm{Z}$ axes. Biological samples are often stained with specific fluorescent dye so that the fluorescent light from the illuminated spot is collected into the objective and transformed by a photodiode in electrical signal processed by a computer. The optical reconstruction of all the pixel information was assembled yielding a high contrast and high resolution threedimensional image. This technique has been widely used in the study of biofilm, especially to study EPS components and the biofilm cell itself. ${ }^{2,26}$

Using CSLM, the image of biofilm formed on various surfaces, even transparent or non transparent surfaces such as silicone, polyethylene or stainlsess steel, polymethyl metacrylat, can be depicted very well as shown in FIGURE $1 .^{27}$ The main limitations of this method are that CLSM allows only a semiquantitative investigation and that only few fluorescent stains can be employed simultaneously showing just a couple of component in the same image. ${ }^{25}$

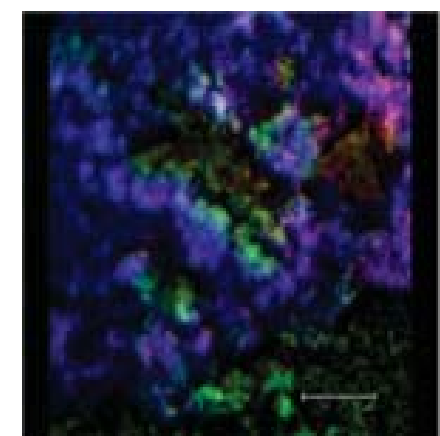

A

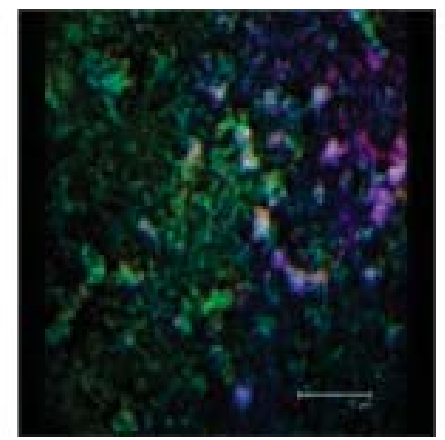

B

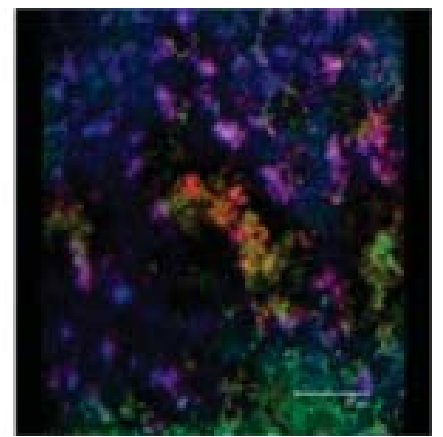

C

FIGURE 1. Confocal laser scanning microscopy images in projected top-view and sideview of $24 \mathrm{~h}$ biofilm of $S$. epidermidis grown on polyethylene (A), polymethylmethacrylate (B) and stainless steel (C) with Baclight dead/live stain yielding red and green for dead and live bacteria, respectively, and calcofluorwhite staining to visualize slime (blue) ${ }^{27}$

\section{Scanning Electron Microscope (SEM)}

Scanning electron microscope is a wellestablished basic method to observe the morphology of bacteria adhered on a material surfaces, the morphology of the material surface, and the relationships between them. Scanning electron microscope has been used for enumeration of adhered bacteria or tissue large number of samples. It is as a key technique that provides also information about the morphology 
of biofilm and presence of EPS. Biofilm morphology and mass are important characteristics that control the kinetics of substrate removal by biofilms. Scanning electron microscope is a powerful technique for revealing the fine structure of living systems and has been applied to biofilms. ${ }^{2,28}$ It has also been of special importance in elucidating biofilm structure for understanding the physiology and ecology of these microbial systems. In general, application of SEM techniques may present many advantages, the more important are: (i) higher resolution of visualization microbial biofilms than other imaging techniques, typically $3.5 \mathrm{~nm}$, (ii) able to measure and quantify data in three dimensions. However, this technique utilizes graded solvents (alcohol, acetone, and xylene) to gradually dehydrate the specimen prior to examination, since water of hydration is not compatible with the vacuum used with the electron beam. ${ }^{29}$ While any pretreatment can alter specimen morphology, drying appears to significantly alter biofilms due to EPS polymers collapsing. The dehydration process results in significant sample distortion and artifacts; the extracellular polymeric substances, which are approximately 95\% water and the liquid loss led them to appear more like fibers surrounding the cells than like a gelatinous matrix. Therefore, procedures are required which do not destroy the structure of the samples or cause artefacts. Coating with a conductive material, such as gold are necessary to overcome this problem. ${ }^{2,30}$

\section{Environmental Scanning Electron Microscope (ESEM)}

Environmental scanning electron microscope allows investigation of bacteria without any dehydration, fixation or coating of bacteria in the natural state. This is a clear advantage. Furthermore, three-dimensional visualization of the structures is sometimes limited. The standard electron microscopic technique used for the evaluation of ultrathin sections is transmission electron microscopy (TEM). An important advantage of TEM is its high resolution of down to $0.1 \mathrm{~nm} .{ }^{31}$ The indispensable fixation is typically carried out with glutaraldehyde or osmium tetroxide, which also stains lipids. A different option is cryofixation at $-135^{\circ} \mathrm{C}$ to help avoid artefacts. However, the contrast is rather low. Additionally, staining with heavy elements such as lead citrate or uranyl acetate for the purpose of contrasting is often required. Summing up, it may be stated that TEM is an excellent method for the visualization of bacteria and the surrounding extracellular matrix as well as of the conditioning film or the dental pellicle but it is a very time-consuming and complex technique. ${ }^{30,32}$ Nonetheless, due to its high resolution, TEM is still considered to be a gold standard in electron microscopy for biofilm images. ${ }^{30}$

\section{Fluorescence In Situ Hybridization (FISH)}

Fluorescence in situ Hybridization technique is a genetic approach using oligonucleotide probes labelled with fluorescent dyes. These probes can be specifically designed to bind rRNA, particularly abundant in viable cells or to bind a specific molecule representative of a specific target of interest. A large number of intact ribosomes representing the biological activity of the tested cells is a prerequisite for this method, so that apparently only vital bacteria are stained. ${ }^{30}$ Fluorescence in situ hybridization can detect viable but not cultivable bacteria or bacteria with low metabolism (dormant) in biofilm. It has the advantage that bacteria do not need to be cultured before detection and this would lead to a reduced time to identification of the infecting organism. ${ }^{33}$ In clinical practice, FISH can be used in situations in which quick identification of the infection organism has an 
advantage in the treatment of the patient. Also, different studies have shown that not all of the bacteria in a specimen can be cultured because of some of the bacteria having entered a nonculturable state, the culture conditions not being suitable or the patient having already been treated with antibiotics. ${ }^{34}$

Combining FISH technique with confocal laser scanning microscopy is possible for the identification and topographical visualization of different species in a multispecies biofilm. The principal disadvantages are related to the complex preparation procedure, limited number of oligonucleotide probes availability, staining only bacteria with intact membranes, and to the fact that the technique is time consuming and expensive. Moreover this technique provides highly specific identification of different bacterial species but semiquantitative results. ${ }^{28}$

Another technique to visualize biofilm's presence directly from clinical sampel is reported by Hochstim et al. ${ }^{35}$ by using hematoxylin-eosin (HE) staining. It is a reliable and available method for the detection of bacterial biofilm in chronic infectious disease. Histologically, biofilm appears as clusters of basophilic bacteria and host cells entrapped in a layer of extracellular polymeric substance resting on the surface epithelium. Because there is increasing evidence that biofilm plays an important role in many chronic diseases, it is important to identify easier and cheaper methods to study biofilm in clinical samples. In particular, the wide availability of HE staining of surgical specimens through clinical pathology laboratories makes this a highly practical method for detecting biofilm in clinical practice. ${ }^{35}$ This assay can not identifiy and differentiate the bacterial composition of biofilm and just present an early screening of biofilm-related infection in clinical sampel.

\section{Molecular technique : PCR and Real time PCR}

Sophisticated molecular techniques are increasingly being used in many areas of microbiology. However, in the case of biofilms, application of such methods often destroys biofilm morphology or architecture due to the DNA/RNA extraction process. Polymerase chain reaction (PCR) is widely used as diagnostic method. In biofilm, this method allows to identify efficiently the presence of specific genetic sequences related to individual bacterial species which related to its biofilm production.

Nevertheless, PCR as such, is not suitable for quantitative studies of biofilm and, as amplifying indifferently DNA of both viable and dead cells, it cannot be used for enumeration of living cells. Moreover, due to its high sensitivity, false positive results can be expected from natural contamination. To overcome these problems, "Real Time Quantitative-Reverse Transcription-PCR" (qRT-PCR) has been adopted. The qRT-PCR is one of the most powerful and sensitive gene analysis techniques available at now. While in traditional PCR analysis, results are collected at the end of the reaction, during qRT-PCR, the fluorescent signal is measured in real time at each amplification cycle and is directly proportional to the number of amplicons generated.

Real Time PCR showed a meaningful tool to compare genes expression involved in biofilm formation of clinical isolates under different environmental exposure. Using these data, the regulation of biofilm formation can be studied more clearly. 27,36,37 FIGURE 2 shows gene expression of icaA in S. epidermidis strains in response to environmental signal. Drawbacks of this method are related to sample preparation that must be free from contaminants and/or PCR inhibitors and the choice of the primers sequence 
to overcome the amplification of gene sequence not functional for the purposes of the investigation. Other limitations of this method are due to the high costs and the difficulty of execution, requiring expensive scientific equipment and skilled technical staff. ${ }^{2,38}$

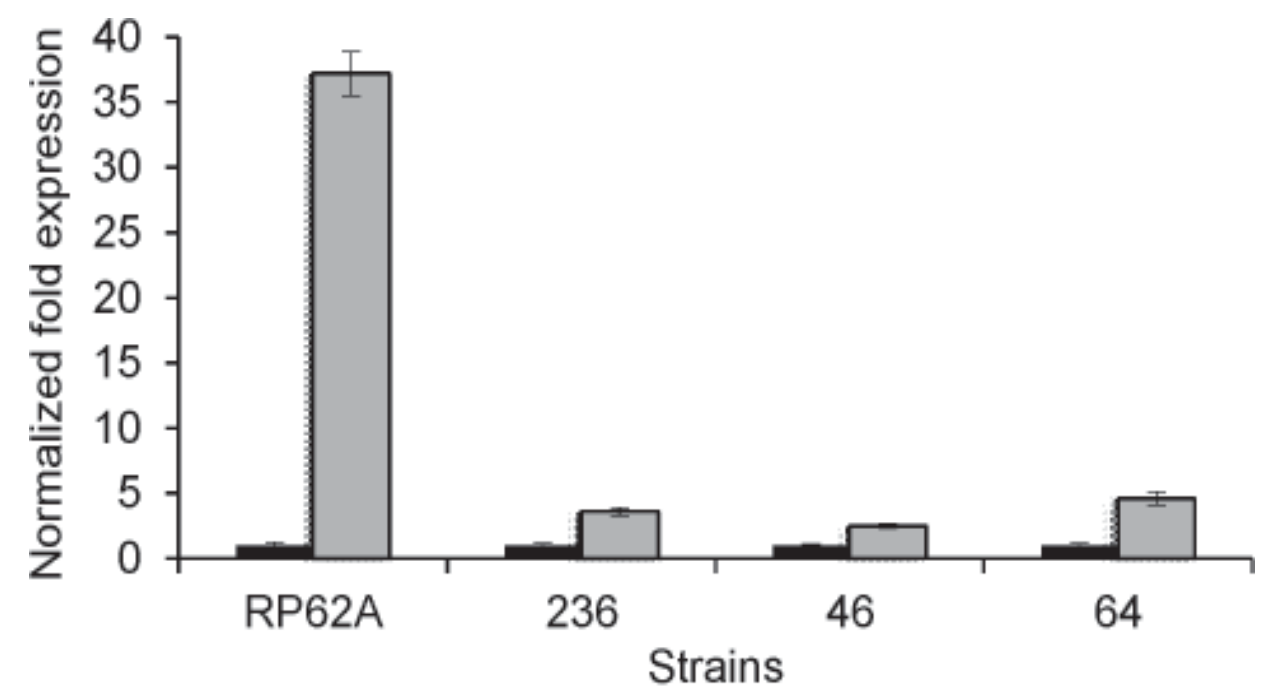

FIGURE 2. Study of gene expression of icaA in S. epidermidis strains in response to environmental signal, e.g. cinnamon oil. The normalized fold-expression of ica $A$ in biofilms exposed to $0.01 \%$ cinnamon for $24 \mathrm{~h}$ (grey bars) was plotted against unexposed control biofilms (black bars). Y-axis revealed the expression of icaA gene, and $\mathrm{X}$-axis represented the strain of $S$. epidermidis tested. ${ }^{38}$

\section{CONCLUSION}

Recently biofilm-related infection arise as serious problem in medical setting, mainly associated with frequent use of indwelling medical devices. In addition, biofilm research is still a challenging field of interest and the techniques for determination the presence of biofilm cell have undergone rapid progress. However, some of these promising techniques, such as AFM or ESEM, require costly equipment while for others, such as TEM or SEM, extensive preparation of the samples is necessary. The study of biofilm requires multiple approaches able to characterize the different aspects of biofilm. This short review reports only the most common methods used for determination of biofilm presence in vitro. Each of them shows advantages and disadvantages and allows the evaluation of a peculiar aspect of the biofilm. Therefore, the knowledge of the advantages and limitations of the different methods as well as the multidisciplinary expertise of the researchers are necessary prerequisites allowing the right choice of the methodologies to be used.

\section{ACKNOWLEDGEMENT}

The author would like to thanks to Willy de Haan for her help to provide the real time PCR data.

\section{REFERENCES}

1. Sawhney R, Berry V. Bacterial biofilm formation, pathogenicity, diagnostics and control: An overview. Indian J Med Sci 2009; 63(7):313-21. 
2. Pantanella F, Valenti P, Natalizi T, Passeri D, Berlutti F. Analytical techniques to study microbial biofilm on abiotic surfaces: pros and cons of the main techniques currently in use. Ann Ig 2013; 25(1):31-42.

3. Anonim. National Heart Lung and Blood Institute. Research on microbial biofilms, 2002 (cited 2014 June 1) Available from : URL : grants.nih.gov

4. Donlan RM. Biofilms and device-associated infections. Emerg Infect Dis 2001; 7(2):277-81.

5. Reid G. Biofilms in infectious disease and on medical devices. Int J Antimicrob Agents 1999; 11(3-4):223-6.

6. Sanchez CJ Jr, Mende K, Beckius ML, Akers KS, Romano DR, Wenke JC, et al. Biofilm formation by clinical isolates and the implications in chronic infections. BMC Infec Dis 2013; 29(13):47-55.

7. Christensen GD, Baddour LM, Simpson WA. Phenotypic variation of Staphylococcus epidermidis slime production in vitro and in vivo. Infect Immun 1987; 55(12):2870-7.

8. van Merode AEJ. Role of surface charge heterogeneity in Enterococcus faecalis adhesion and biofilm formation. [PhD Thesis]. Groningen: Rijksuniversiteit; 2006: 103-14.

9. Freeman DJ, Falkiner FR, Keane CT. New method for detecting slime production by coagulase negative staphylococci. J Clin Pathol 1989; 42(8):872-4.

10. Mariana NS, Salman SA, Neela V, Zamberi S. Evaluation of modified Congo red agar for detection of biofilm produced by clinical isolates of methicillin-resistance Staphylococcus aureus. African J Microbiol Res 2009; 3:330-8.

11. Mathur T, Singhal S, Khan S, Upadhyay DJ, Fatma T, Rattan A. Detection of biofilm formation among the clinical isolates of staphylococci: An evaluation of three different screening methods. Indian J Med Microbiol 2006; 24(1):25-9.

12. Fletcher $\mathrm{M}$. The effects of culture concentration and age, time, and temperature on bacterial attachment to polystyrene. Can J Microbiol 1977; 23:1-6.

13. Stepanovic S, Vukovic D, Dakic I, Savic B, SvabicVlahovic M. A modified microtiter-plate test for quantification of staphylococcal biofilm formation. J Microbiol Methods 2000; 40(2):175-9.

14. Christensen GD, Simpson WA, Younger JJ, Baddour LM, Barrett FF, Melton DM, et al.
Adherence of coagulase-negative staphylococcito plastic tissue culture plates: a quantitative model for the adherence of staphylococci to medical devices. J Clin Microbiol 1985; 22(6):996-1006.

15. Li X, Yan Z, Xu J. Quantitative variation of biofilms among strains in natural populations of Candida albicans. Microbiology 2003; 149(Pt 2):353-62.

16. Pantanella F, Berlutti F, Passariello C, Sarli S, Morea C, Schippa S. Violacein and biofilm production in Janthinobacterium lividum. J Appl Microbiol 2007; 102(4):992-9.

17. Agarwal RK, Singh S, Bhilegaonkar KN, Singh VP. Optimization of microtitre plate assay for the testing of biofilm formation ability in different Salmonella serotypes. Int Food Res J 2011; 18:1493-8.

18. Hassan A, Usman J, Kaleem F, Omair M, Khalid A, Iqbal M. Evaluation of different detection methods of biofilm formation in the clinical isolate. Braz J Infect Dis 2011; 15(4):305-11.

19. Taj Y, Essa F, Aziz F, Kazmi SU. Study on biofilmforming properties of clinical isolates of Staphylococcus aureus. J Infect Dev Ctries 2012; 6(5):403-9.

20. Peterson SB, Irie Y, Borlee BR. Different methods for culturing biofilms in vitro. In: Bjamsholt $\mathrm{T}$, Moser C, Jensen PO, Hoiby N editors. Biofilm Infections. Kopenhaen: Springer Publisher 2011; 251-66.

21. Ceri H, Olson ME, Stremick C, Read RR, Morck D, Buret A. The calgary biofilm device: new technology for rapid determination of antibiotic susceptibilities of bacterial biofilms. J Clin Microb 1999; 37(6):1771-6.

22. Azevedo N, Lopes S. Time to "go large” on biofilm research: advantages of an omics approach. Biotechnol Lett 2009; 31(4):477-85.

23. Benoit MR, Conant CG, Ionescu-Zanetti C, Schwartz M, Matin A. New device for highthroughput viability screening of flow biofilms. Appl Environt Microbiol 2010; 76(13):4136-42.

24. Gomes LC. Optimization of cultivation conditions for $E$. coli biofilm formation in microtiter plates. [Master Dissertation]. Porto: Porto University; 2011.

25. Bradshaw DJ and Marsh PD. Novel microscopic methods to study the structure and metabolism of oral biofilms. In: Wilson $\mathrm{M}$ and Devin D editors. Medical Implications of Biofilms. Cambridge: Cambridge University Press 2003; 173-88. 
26. Lawrence JR, Korber DR, Hoyle BD, Costerton JW, Caldwell DE. Optical sectioning of microbial biofilms. J Bacteriol 1991; 173(20):6558-67.

27. Nuryastuti T, Krom BP, Aman AT, Busscher HJ, van der Mei HC. Ica-expression and gentamicin susceptibility of Staphylococcus epidermidis biofilm on orthopedic implant biomaterials. J Biomed Mater Res A 2011; 96(2):365-71.

28. Hannig C, Follo M, Hellwig E, Al-Ahmad A. Visualization of adherent micro-organisms using different techniques. J Med Microbiol 2010; 59(Pt 1):1-7.

29. El Abed S, Ibnsouda SK, Latrache H, Hamadi F. Scanning electron microscopy (SEM) and environmental SEM: suitable tools for study of adhesion stage and biofilm formation. In: Kazmiruk V editor. Scanning Electron Microscopy. Rejika: In Tech, 2012.

30. Hannig C, Ruggeri A, Al-Khayer B, Schmitz P, Spitzmüller B, Deimling D, et al. Electron microscopic detection and activity of glucosyltransferase B, C, and D in the in situ formed pellicle. Arch Oral Biol 2008; 53(11):1003-10.

31. Bergmans L, Moisiadis P, Van Meerbek B, Quirynen M, Lambrechts P. Microscopic observation of bacteria: review highlighting the use of environmental SEM. Int Endod J 2005; 38(11):775-88.

32. Hannig M, Balz M. Influence of in vivo formed salivary pellicle on enamel erosion. Caries Res 1999; 33(5):372-9.
33. Jansen GJ, Mooibroek M, Idema J, Harmsen HJ, Welling GW, Degener JE. Rapid identification of bacteria in blood cultures by using fluorescently labeled oligonucleotide probes. J Clin Microbiol 2000; 38(2):814-7.

34. Amann RI, Ludwig W, Schleifer KH. Phylogenetic identification and in situ detection of individual microbial cells without cultivation. Microbiol Rev 1995; 59(1):143-69.

35. Hochstim CJ, Choi JY, Lowe D, Masood R, Rice DH. Biofilm detection with hematoxylin-eosin staining. Arch Otolaryngol Head Neck Surg 2010; 136(5):453-6.

36. Nuryastuti T, van der Mei HC, Busscher HJ, Kuijer $\mathrm{R}$, Aman AT, Krom BP. recA mediated spontaneous deletions of the icaADBC operon of clinical Staphylococcus epidermidis isolates: a new mechanism of phenotypic variations. Antonie Van Leeuwenhoek 2008; 94(2):317-28.

37. Nuryastuti T, van der Mei HC, Busscher HJ, Iravati S, Aman AT, Krom BP. Effect of cinnamon oil on icaA expression and biofilm formation by Staphylococcus epidermidis. Appl Environ Microbiol 2009; 75(21):6850-5.

38. Suzuki N, Yoshida A, Nakano Y. Quantitative analysis of multi-species oral biofilms by TaqMan real-Time PCR. Clin Med Res 2005; 3(3):17685. 